\title{
LEARNING STRATEGIES AND SCHOOL MOTIVATION IN EXPERIENTIAL LEARNING VS. TRADITIONAL LEARNING
}

\author{
Camelia Mădălina Răducu \\ Faculty of Psychology and Educational Sciences, University of Bucharest (Romania)
}

\begin{abstract}
Introduction: In recent years, European innovation policies in education have focused on preventing early school leaving and functional illiteracy. In this context of innovation in education, experiential learning has proven to have unique qualities for both teachers and students. Thus, the main motivation of this paper was to show that experiential teaching methods and techniques in primary education are able to produce significant improvements in learning strategies and school motivation in young students.

Objectives: The aim of this this study was to explore the differences in learning strategies and school motivation on young students who had benefitted from Experiential Learning, in contrast with those following direct learning instructional methods

Methods: This study was performed using two groups of subjects. The first group (experimental group) included 60 students taught by experiential methods and the second group (control group) included 60 students taught by traditional methods. All students were in the fourth grade in an urban school. Differences in learning strategies and school motivation were explored by applying School Motivation and Learning Strategies Inventory - SMALSI (Stroud \& Reynolds, 2006) to both the experimental group and the control group. SMALSI is structured in 9 dimensions - 6 strengths: study strategies, note-taking / listening skills, reading / comprehension strategies, writing skills / research, strategies used in tests, techniques for organizing / managing time; and 3 weaknesses are: low academic motivation, test anxiety, concentration difficulties / paying attention. To determine the differences in the students' mean scores, descriptive as well as inferential statistical analyses were performed on the data.

Results: The results showed that an experiential teaching model produces positive results in all evaluated strengths and in two of the three weak points investigated, namely in academic motivation and test anxiety. Statistically insignificant effects are in terms of attention / concentration difficulties, they may be more dependent on physiological and psychological maturation and less on the teaching methods, but also may be a direction of further research.

Conclusions: The findings of this study could significantly help teachers looking for viable solutions to optimize students school results, increase school motivation and improve learning strategies in primary school.
\end{abstract}

Keywords: Experiential learning, learning strategies, school motivation, primary education, traditional learning.

\section{Introduction}

The modernization of education in all its aspects is an increasingly pressing concern in recent years, the need for an in-depth reform being brought more and more often into educational debate. This concern is no longer only on the table of educators and teachers, parents, and children, but also on the table of psychologists, sociologists, health workers and other important political institutions, knowing that education is the key to building a prosperous, stable, supportive, and autonomous society.

In an actual analysis of the needs of education at the level of the individual, J. Delors (2013) enumerated four types of learning: learning to know, learning to do, learning to live with others and learning to become, that ensures success in adult life. It is required that these fundamental types of learning to be built gradually from the first years of schooling to be able to cope optimally with present and future challenges. That is why modern didactics draw attention to the need to shift the emphasis on learning knowledge on the development of personal, unique skills of cognitive, emotional, and social autonomy.

Starting from the desire to identify an experiential model that corresponds as much as possible to the expression abilities of the young pupils and at the same time serves the purpose of optimizing the instructive-educational process of learning to know, do, work with others and become the best own 
version, has emerged a model that interweaves through the richness of techniques and provide freedom of creative expression, experiencing "here and now" the facets of reality. This empirical experiential model has its conceptual methodological roots in the theory of experiential learning developed by D. Kolb (1984).

\section{Experiential learning}

The concept of experiential education gained space at the beginning of the 21 st century and has spread in various fields, bringing multiple benefits in domains like action learning (Francis et al., 2011), service learning (Bielefeldt, Dewoolkar, Caves, Berdanier, \& Paterson, 2011), problem-based learning (Bethell \& Morgan, 2011), adventure education (Timken \& McNamee, 2012), and simulation and gaming (Shields, Zawadzki, \& Johnson, 2011). In the educational field, Experiential Learning Theory (ELT) has been used and delivered instructional programs in K-12 education.

The construction of the theory of experiential learning was based on: The learning model proposed by John Dewey (1938), the research-action model of Kurt Lewin (1940) and Jean Piaget's Theory $(1936,1950)$ on learning and cognitive development. All these theories have led to the definition of learning as a "process in which knowledge is created through the transformation of experience." (Kolb, 1984, p. 67). This definition underlines that knowledge is a process of creative and recreational transformation trough a cyclical process, comprised of four components: a concrete experience, reflection and observation, abstract conceptualization, and experimenting with novel situations.

The unique perspective on experiential learning that can be characterized by 6 principles described in the next sub-items:

- Learning should not be based on the outcome but on the process.

- All learning is relearning, a process in which students' ideas can be examined, tested, and adjusted, as the learning process continues.

- The learning process involves conflict and differences, as a student reflects, thinks, and acts to arrive at a resolution, which, with more learning, will put them back into the cycle of conflict and resolution.

- Learning is a holistic process, not only of cognition, but also of thinking, feeling, perceiving, and behaving.

- Learning evolves through an individual's interaction with the environment and the assimilation of new experiences into existing concepts from previous experiences.

- Learning is created and recreated by the learner (Kolb \& Kolb, 2006).

In terms of experiential learning in primary schools in Romania, this is still in its infancy, being implemented locally with the help of pilot projects and demonstrating its effectiveness through a micro-study which showed that the experiential methodology applied in the case of students in primary classes can produce better results in standardized TIMMS and PIRLS tests in fourth grade (Raducu, 2019).

\section{Objectives}

The general objective of this study is to validate the experiential teaching model in primary education in order to optimize students' personal resources, learning strategies and school motivation.

The specific objectives are to develop students' learning strategies and school motivation through an alternative form of teaching, playful and student-oriented that incorporates concrete experience, reflective observation, abstract conceptualization, and active experimentation in an innovative teaching model. It is expected that by adopting a scientifically reasoned, creative teaching method based on the spiral of complete learning cycles that meet all the educational needs of the student, to improve study strategies and academic motivation by focusing on learning inside-out.

Research questions:

1. Is there a statistically significant difference in the study strategies used by students depending on the training program followed experiential vs. traditional?

2. Is there a statistically significant difference in the note - taking / listening skills used by students depending on the training program followed experiential vs. traditional?

3. Is there a statistically significant difference in the reading / comprehension strategies used by students depending on the training program followed experiential vs. traditional?

4. Is there a statistically significant difference in the writing / research skills used by students depending on the training program followed experiential vs. traditional?

5. Is there a statistically significant difference in the strategies used in tests used by students depending on the training program followed experiential vs. traditional?

6. Is there a statistically significant difference in the techniques of organizing and managing time used by students depending on the training program followed experiential vs. traditional? 
7. Is there a statistically significant difference in the academic motivation of students depending on the training program followed experiential vs. traditional?

8. Is there a statistically significant difference in test anxiety of students depending on the training program followed experiential vs. traditional?

9. Is there a statistically significant difference in the concentration difficulties / attention of students depending on the training program followed experiential vs. traditional?

\section{Methods}

\subsection{Design}

The design of this research is an experimental one. The testing of the hypotheses of this study was performed by comparing the averages of the scores obtained in the SMALSI test of two independent samples: one trained by traditional methods and the other trained by experiential methods. The data were evaluated transversally in a single moment of the research.

The dependent variables of the research are represented by the learning strategies and the school motivation of the students, the measured operational constructs being constituted by 7 strong points of the students and 3 weak points. Strengths are: study strategies, note-taking / listening skills, reading / comprehension strategies, writing / research skills, test strategies, organizing techniques/ time management. Weaknesses are: low academic motivation, test anxiety, concentration difficulties / paying attention.

The independent variable is the type of training followed during the primary education cycle, namely training through traditional methodology or training through experiential methodology.

\subsection{Data collection procedure}

The data needed to conduct this study were collected in June 2019, by applying SMALSI test to 60 students (control group) trained by traditional methods and 60 students trained by experiential methods (experimental group). The students were in the fourth grade in an urban school from Bucharest. The questionnaires were applied in groups, in the presence of the teacher, who had the role of helping students to understand the items that raise comprehension problems. The application of the questionnaires was preceded by the request for parental consent.

\subsection{Instruments}

The instrument used was the School Motivation and Learning Strategies Inventory - SMALSI (Stroud \& Reynolds 2006). The instrument is described below.

SMALSI - the children's version, is a self-assessment questionnaire, designed to assess 9 constructs mainly associated with school motivation and learning strategy, 6 of which focus on the student's strengths and 3 visit his weaknesses. Depending on the reading skills of the examined student, the SMALSI questionnaire will be completed in 20-30 minutes.

The result of the evaluation is the following indicators, specific for:

Student strengths:

Study Strategies (STUDY) investigates the ability to select important information, making connections between information already assimilated and recently assimilated, memorization strategies for encoding information. The STUDY scale contains 14 items.

Notation / Comprehension Skills (NOTAT) measures the ability to select important information for efficient notetaking and organization. The NOTAT scale contains 18 items.

Reading / Comprehension Strategies (READING) proposes measuring the ability to read, monitor and reread texts, including self-testing to ensure understanding of the content. The READ scale contains 15 items.

Writing / Research Skills (WRITING) investigates the ability to research topics in any way, organizing written projects, checking for mistakes made. The WRITING scale contains 11 items.

Test Strategies (TESTs) measure the effectiveness of participating in tests / examinations, including the elimination of improbable answers and strategic guessing. The TEST scale contains 12 items.

Time Management / Organizational Techniques (TIMORG) investigates the efficient use of time to complete homework, awareness of the time required for school assignments and the ability to organize materials received at school and study, structuring tasks, including homework and other projects. The TIMORG scale contains 18 items.

\section{Student weaknesses:}

Low Academic Motivation (MOTSCA) measures the lack of intrinsic motivation needed to get involved and succeed in academic tasks. The MOTSC scale contains 19 items.

Test Anxiety (TANX) assesses the student's experience of showing test / examination anxiety symptoms, poor test performance caused by excessive worry. The TANX scale contains 21 items. 
Concentration / Attention Difficulties (DIFCON) investigates the difficulty of attending classes and other school tasks, focusing attention on performance, and avoiding disruptive elements. The DIFCON scale contains 18 items.

\subsection{Statistical approach}

According to the methodological recommendations, the testing of the hypotheses was preceded by the analysis of the correlation coefficients between the dependent variables and the socio-demographic variables that can play the role of covariant variables, since they can have effects on students' performance in assessments. Given that the relationships between socio-demographic variables and dependent variables are of low and very low intensity $(r<.30)$, we cannot discuss the existence of covariant variables.

\subsection{Results}

Table 1. presents the descriptive statistics and Pearson correlation coefficients between the variables analyzes in this study.

Table 1. Descriptive statistics and Pearson correlation coefficients between the variables.

\begin{tabular}{|c|c|c|c|c|c|c|c|c|c|}
\hline Variabiles & 1 & 2 & 3 & 4 & 5 & 6 & 7 & 8 & 9 \\
\hline 1 Study & - & & & & & & & & \\
\hline 2 Notat & $.83^{* * *}$ & - & & & & & & & \\
\hline 3 Read & $.19^{*}$ & $.23^{*}$ & - & & & & & & \\
\hline 4 Writing & $.81^{* * *}$ & $.79^{* * *}$ & $.18^{*}$ & - & & & & & \\
\hline 5 Test & $.77^{* * *}$ & $.81^{* * *}$ & $.21^{*}$ & $.86^{* * *}$ & - & & & & \\
\hline 6 Timorg & $.78^{* * *}$ & $.80^{* * *}$ & $.20^{*}$ & $.82^{* * *}$ & $.89^{* * *}$ & - & & & \\
\hline 7 Motsca & $-.57^{* * *}$ & $-.55^{* * *}$ & $-.13^{*}$ & $-.62^{* * *}$ & $-.57^{* * *}$ & $-.58^{* * *}$ & - & & \\
\hline 8 Tanx & $-.60^{* * *}$ & $-.51^{* * *}$ & $-.26^{* *}$ & $-.62^{* * *}$ & $-.67^{* * *}$ & $-.63^{* * *}$ & $.62^{* * *}$ & - & \\
\hline 9 Difcon & $-.61^{* * *}$ & $-.58^{* * *}$ & $-.22^{*}$ & $-64^{* * *}$ & $-.63^{* * *}$ & $-.66^{* * *}$ & $.61^{* * *}$ & $.63^{* * *}$ & - \\
\hline$M$ & 23.83 & 36.58 & 30.44 & 21.23 & 26.48 & 31.86 & 16.48 & 19.33 & 10.85 \\
\hline$S D$ & 2.57 & 3.75 & 16.93 & 2.58 & 3.16 & 3.92 & 2.97 & 5.00 & 2.82 \\
\hline
\end{tabular}

The $t$ test for independent samples was applied to compare the scores obtained by students in the SMALSI test according to the type of teaching. At the level of study strategies, students coming from the class with experiential teaching style $(\mathrm{M}=24.83, \mathrm{SD}=2.13)$ have significantly higher scores $(\mathrm{t}(118)=4.62, \mathrm{p}<.001, \mathrm{~d}=0.84)$ compared to participants who they benefited from the traditional teaching style $(\mathrm{M}=22.83, \mathrm{SD}=2.59)$.

At the level of taking notes, students coming from the class with experiential teaching style $(\mathrm{M}=37.78, \mathrm{SD}=3.24)$ have significantly higher scores $(\mathrm{t}(118)=3.68, \mathrm{p}<.001, \mathrm{~d}=0.67)$ compared to participants who benefited from the traditional teaching style $(\mathrm{M}=35.38, \mathrm{SD}=3.87)$.

At the level of reading strategies, students coming from the class with experiential teaching style $(\mathrm{M}=33.25, \mathrm{SD}=3.78)$ have significantly higher scores $(\mathrm{t}(118)=0.12, \mathrm{p}=.549, \mathrm{~d}=-0.02)$ compared to participants who benefited from the traditional teaching style $(\mathrm{M}=30.63, \mathrm{SD}=23.74)$.

In terms of writing skills, children who learn based on an experiential teaching style $(\mathrm{M}=22.00$, $\mathrm{SD}=2.50)$ obtained significantly different scores $(\mathrm{t}(118)=3.39, \mathrm{p}<.001, \mathrm{~d}=0.62)$ compared to students coming from classes with traditional teaching style $(\mathrm{M}=20.47, \mathrm{SD}=2.45)$.

Regarding the strategies used in the test, the children who learn based on an experiential teaching style $(\mathrm{M}=27.48, \mathrm{SD}=2.83)$ obtained significantly different scores $(\mathrm{t}(118)=3.65, \mathrm{p}<.001, \mathrm{~d}=0.67)$ compared of students coming from classes with traditional teaching style $(\mathrm{M}=25.48, \mathrm{SD}=3.18)$.

At the level of organizational techniques coming from the class with experiential teaching style $(\mathrm{M}=33.15, \mathrm{SD}=3.71)$ they obtained significantly higher scores $(\mathrm{t}(118)=3.81, \mathrm{p}<.001, \mathrm{~d}=0.70)$ compared to the participants who they benefited from the traditional teaching style $(\mathrm{M}=30.57$, $\mathrm{SD}=3.71)$

Regarding the academic motivation, the children who learn based on an experiential teaching style $(\mathrm{M}=15.67, \mathrm{SD}=2.78)$ obtained significantly lower scores $(\mathrm{t}(118)=-3.09, \mathrm{p}<.001, \mathrm{~d}=-0.56)$ compared to students who come from classes with traditional teaching style $(\mathrm{M}=17.28, \mathrm{SD}=2.95)$.

Regarding test anxiety, children who learn based on an experiential teaching style $(\mathrm{M}=17.42$, $\mathrm{SD}=4.63)$ obtained significantly lower scores $(\mathrm{t}(118)=-4.51, \mathrm{p}<.001, \mathrm{~d}=-0.82)$ compared to students who come from classes with traditional teaching style $(\mathrm{M}=21.23, \mathrm{SD}=4.65)$.

At the level of concentration difficulties, students coming from the class with experiential teaching style $(\mathrm{M}=10.63, \mathrm{SD}=2.97)$ did not obtain significantly lower scores $(\mathrm{t}(118)=-0.84, \mathrm{p}=.201, \mathrm{~d}=0.15)$ compared with participants who benefited from the traditional teaching style $(\mathrm{M}=11.07, \mathrm{SD}=2.67)$. 


\section{Discussions}

The main aim of this research was to determine whether there are statistically significant results between learning strategies and school motivation depending on the training methodology followed, experiential or traditional, in primary school in 9 different areas: study strategies, note-taking / listening skills , reading / comprehension strategies, writing / research skills, strategies used in tests, time organization / management techniques, academic motivation, test anxiety, concentration difficulties / paying attention. The findings of this study could significantly help teachers looking for viable solutions to optimize students' school results in primary school, increase school motivation and improve learning strategies.

Frequently, learning strategies and academic motivation in the early stages of education have been considered predictors of success in adult life (Brackney \& Karabenick, 1995). Moreover, we could consider that the identification of a student's strengths and weaknesses from the first years of schooling can be a factor in preventing repeated failures and stimulating academic success. Given that it is not always possible to investigate and monitor learning strategies for each student, due to limited resources, building a teaching model that can optimally stimulate all these psychological constructs can be an optimal solution to support both of students as well as teachers.

This paper takes a step further in discovering the link between learning strategies, school motivation in students and the type of training followed, traditional methods and techniques or through experiential methods and techniques. The results showed that an experiential teaching model produces positive results in all evaluated strengths: study strategies, note-taking / listening skills, reading / comprehension strategies, writing / research skills, test strategies, organizing techniques / time management, and in two of the three weak points investigated, namely in academic motivation and test anxiety. Statistically insignificant effects are in terms of paying attention / concentration difficulties, one explanation being that they may be more dependent on physiological and psychological maturation and less on the teaching methodology but is still a direction of further research.

\section{References}

Bielefeldt, A. \& Dewoolkar, M. \& Caves K. \& Berdanier, B. \& Paterson, K. (2011). Diverse Models for Incorporating Service Projects into Engineering Capstone Design Courses. International Journal of Engineering Education. 27. 1206-1220.

Brackney, B. E. \& Karabenick, S. A (1995). Psychopathology and academic performance: The role motivation and learning strategies. Journal of Counseling Psychology, v42 n4 p456-65

Delors, J. (2013). The treasure within: Learning to know, learning to do, learning to live together and learning to be. What is the value of that treasure 15 years after its publication?. International Review of Education, 59(3), 319-330.

Francis, H. \& Cowan J. (2008). Fostering an action-reflection dynamic amongst student practitioners. Journal of European Industrial Training, 32 (5), pp. 336-346

Kolb, A. \& Kolb, D. (2006). Learning styles and learning spaces: A review of the multidisciplinary application of experiential learning theory in higher education. Learning Styles and Learning: A Key to Meeting the Accountability Demands in Education. 190-220.

Kolb, D., Yeganeh, B. (1984). Experiential learning: experience as the source of learning and development Englewood Cliffs, NJ: Prentice-Hall.

Morgan, K. \& Bethell S. (2011). Problem-based and experiential learning: Engaging students in an undergraduate physical education module. The Journal of Hospitality Leisure Sport and Tourism. 10. 128-134. 10.3794/johlste.101.365.

Raducu, C. (2019). Experiential vs. Traditional. Journal of Experiential Psychoteraphy nr 22(3)(87)), pag 60-67

Shields S. A.\& Zawadzki M. J. \& Johnson R.N. (2011). The Impact of Workshop Activity for Gender Equity Simulation in the Academy (WAGES-Academic) in Demonstrating Cumulative Effects of Gender Bias. Journal of Diversity in Higher Education 4, no. 2: 120-29.

Stroud, K. C. \& Reynolds, C. R. (2006). School Motivation and Learning Strategies Inventory (SMALSI). Los Angeles, CA: Western Psychological Services.

Timken, G. \& McNamee, J. (2012). New Perspectives for Teaching Physical Education. Journal of Teaching in Physical Education. 31. 10.1123/jtpe.31.1.21. 